\title{
Factors driving embodied carbon in international trade: A multi-regional input-output gravity model
}

\begin{abstract}
Concerns about the effects and consequences of climate change have notably increased in recent decades. Despite large advances in the understanding of this phenomenon, further research into the determinants of gas emissions is necessary, to shed light on the responsibilities of producers and consumers, and their potential contribution to mitigation strategies. This paper studies the trajectories and determinants of carbon embodied in world trade during a period of fifteen years. Our methodology relies on a multi-regional input-output model, environmentally extended. Drawing on data from the World Input-Output Database, we estimate embodied emissions in bilateral flows. Then, we assess the determinants of $\mathrm{CO} 2$ emissions embodied in trade, combining input-output modelling with trade gravity panel data analysis. This paper offers a methodological approach that explains and quantifies the underlying factors of carbon trade, integrating the production and consumption perspectives and considering the geographical, structural, and institutional context of countries.
\end{abstract}

Keywords: CO2 embodied emissions, international trade, MRIO, gravity

Acknowledgements: We would like to thank the anonymous referees and Prof. Michael Lahr for his valuable feedback. This work has been partially supported by the Ministry of Science and Innovation of the Spanish Government (projects ECO2015-65582, ECO2016-74940 and ECO2016-75927-R) and the Department of Science, Technology and Universities of the Government of Aragon (Research Groups “Agrifood Economy, Globalization, Economic Development and Environment (19th - 21st Century)” and "Growth, Demand and Natural Resources").

Disclosure statement: No potential conflict of interest is reported by the authors. 


\section{Introduction}

The 2015 Paris Agreement recognizes that climate change represents an "urgent and potentially irreversible threat to human societies and the planet”. It encourages the widest possible global cooperation to reduce greenhouse gas (GHG) emissions substantially. A total of 195 countries have agreed a global plan. Its objective is to limit warming to below $2^{\circ} \mathrm{C}$, relative to pre-industrial era levels (FCCC/CP/2015/L.9/Rev.1).

The relationship between economic activity and GHG emissions has been widely documented (e.g., Kaya 1990; Alcamo et al. 1995; Alcamo 2008; Malik et al. 2016). The role that the economic system (businesses, consumers, local and international institutions) plays in the generation of emissions suggests that a strategic design towards a low-carbon world would require on the order of a 40\% and 70\% reduction in GHG emissions by 2050 (IPCC, 2014). The interconnections within the system tell us that both consumers and producers are responsible for pollutant emissions. From the production side, industrial processes, particularly those burning fossil fuels, are main determinants of GHG emissions. The use of fossil fuels has more than tripled since 1960 (WRI, 2015). Moreover, the advent of freer international trade has enabled consumption to be met through increasingly globalized supply chains (Yu et al. 2013); so the effects of consumer behavior on the environment have also been increasingly spread around the globe.

The impacts of trade on the environment have been assessed for $\mathrm{CO}_{2}$ emissions (Munksgaard and Pedersen, 2001; Sánchez-Chóliz and Duarte, 2004; Wiedmann, 2009; Yang et al., 2016), finding evidence of carbon leakage (Chen et al., 2010; He and Fu, 2014) and the 'pollution haven' hypothesis (PHH) (Cole, 2004a; Copeland, 2008; López et al., 2013). Multiregional input-output (MRIO) models, which display the domestic and foreign interdependencies between sectors and countries and describe global supply chains, have been used widely to examine these impacts (see Wiedmann et al. 2007; Wiedmann 2009; Duarte and Yang 2011 for a review). They allow linking the consumption and production perspectives (Lenzen et al., 2007) and exploring their main drivers (Xu and Dietzenbacher, 2014). In this line, the development of such empirical databases as EORA (Lenzen et al., 2013), EXIOBASE (Tukker et al., 2009), GTAP (Andrew and Peters, 2013), OECD (Nakano et al., 2009) and WIOD (Dietzenbacher et al., 2013) have facilitated these studies. In all, the multisectoral, multicountry and temporal perspectives are crucial to understanding economic growth, and technological 
and structural change, and to evaluate the existence of trends in agent's behavior that may anticipate the reliability of different scenarios concerning the future.

Structural decomposition analysis (SDA), an analytical technique used to quantify the factors driving change in a dependent variable, has been one of the preferred methodologies to study the drivers behind environmental impacts, and their distribution along supply chains (for reviews, c.f. Su and Ang, 2012; Wang et al., 2017). A main advantage is its explanatory power in identifying the main proximate causes behind changes in environmental impacts, using disaggregated sectoral information with as little as two years of data. As Wang et al. (2017) acknowledge, SDA lacks a flexible modelization of qualitative factors and cannot capture endogenous effects, given their rigid functional form. In this line, panel data econometric analysis can complement SDA studies; it enables measurement of linkages between carbon trade and its main contributors, often controlling for quantitative factors included in SDA studies, but enabling other qualitative determinants as well.

More concretely, two significant issues have not been addressed in studies of carbon trade using SDA applied to MRIO. First, SDA cannot explicitly capture the spatial character of trade flows - that is, the role of distance in the structure of the supply chain although it is implicit in the MRIO interregional trade flows. As Yu et al. (2013) recognize, global supply chains increasingly involve great distances; so the importance of this item is enhanced at least in instances of international MRIO analyses. Second, country- and time-specific variables-e.g., the energy mix, ${ }^{1}$ commercial regulations, and commitment to international agreements—also explain the size, patterns, and evolution of direct and indirect emissions embodied in trade. Despite the advantages of econometric models, it is important to acknowledge that their use requires much more data-i.e., time series for all countries in the sample_-and that they may not always be as "good" as SDA in quantifying structural and compositional changes.

Thus we aim to identify the drivers of global $\mathrm{CO}_{2}$ emissions by studying the role of trade and its main driving factors in the generation of emissions through global supply chains. By acknowledging the multisectoral character of economies, the increasing globalization of supply chains, and the need for an integrated framework, even when

\footnotetext{
${ }^{1}$ Note that $\mathrm{WIOD} \mathrm{CO}_{2}$ emissions are disaggregated considering their energetic source, apart from the sector detail. Therefore, it is possible to examine the different energy mixes across countries and to evaluate their changes over time (see Genty et al., 2012). As an example, during the period 1995-2009 around $75 \%$ of direct $\mathrm{CO}_{2}$ emissions in the U.S.A. were generated by coal, gasoline, and natural gas.
} 
bilateral relationships of countries are analyzed, we build on the MRIO framework and the tradition of trade gravity to specify a model explaining the common patterns and country-specific factors influencing $\mathrm{CO}_{2}$ emissions embodied in trade. In this regard, this paper contributes to the scientific literature by analyzing the main determinants behind changes in all $\mathrm{CO}_{2}$ emissions generated and distributed through international trade along global supply chains. As Johnson and Noguera (2017, p. 911) acknowledge "because the value-added content is falling over time, shifting from gross to value-added export data in empirical applications is more important now than ever before ”.

The research approach that we apply allows us to address the complexity of the trade-emissions nexus, integrating the production and consumption perspectives, and considering the geographical, structural, and institutional context of countries. As a result, two additional issues arise: we examine the PHH in a new, global context by evaluating whether a country's level of economic development is important in determining the amount of emissions embodied in trade, and we show the different role of geographical distance in GHG generation through (1) direct trade flows; and, (2) embodied trade flows.

Specifically, we assess the PHH, i.e., the notion that richer countries "externalize" emissions and that the level of development is a determinant of carbon trade. In other words, we analyse whether globalization plays a role in the reallocation of carbonintensive activities in the least developed areas. The PHH has been evaluated using inputoutput models (e.g., López et al., 2013; Zhang et al., 2017) and econometrics (e.g., He, 2006; Koźluk and Timiliotis, 2016; Millimet and Roy, 2016; Tang, 2015). For the first time, we present a framework that combines both input-output modelling and panel data to analyse the PHH. Additionally, we study the relationship between carbon trade and geographical factors, considering the complexity of global supply chains. That is, we benefit from the value added of MRIO models, which enable tracking of the carbon incorporated in trade flows, not only directly but also indirectly through the exchange of intermediate goods and services. Finally, we study the role of institutional agreements as accelerators or retardants of carbon trade. In doing so, we control for its endogeneity in the model.

Today we find studies that link input-output and gravity models (Aichele and Felbermayr, 2015; Caliendo and Parro, 2015; Guilhoto et al., 2015; Noguera, 2012). However, this is, to the best of our knowledge, the first work to use a combined MRIOgravity approach to study the determinants of carbon trade accounting for the 
fragmentation in global value chains. Moreover, the broad regional and sectoral coverage of world trade in the sample, together with a temporal perspective, are significant strengths of this work, providing the analysis with a truly global perspective.

\section{Materials and methods}

Using the MRIO tables from the World Input-Output Database (WIOD) (Timmer et al., 2015) and data on $\mathrm{CO}_{2}$ emissions from the environmental sources of WIOD (Genty et al., 2012), we estimate $\mathrm{CO}_{2}$ emissions embodied in bilateral exports. This variable reports the bilateral exchanges of $\mathrm{CO}_{2}$ (in kilotons/year) for 39 countries (see the list of countries in the Appendix) from 1995 to 2009, covering between 80\% and 90\% of total international trade during these years. World input-output tables (WIOTs) describe the economic interrelations among 35 sectors ( $i$ and $j$ hereafter) and 41 countries ( $r$ and s hereafter) in the global economy, ${ }^{2}$ which differentiate between intermediate and final demands. WIOTs increasingly are used to study global supply chains, as well as to track down the environmental and social impacts of economic activity in the world. As acknowledged by Rahman et al. (2017), the use of WIOD, in particular, presents several strengths: its WIOTs are obtained using public and official data, built on supply and use tables, comparable to national accounts and available in current and previous year prices. Additionally, WIOD offers time series WIOTs and is harmonised with environmental satellite accounts, being an optimal database to study the dynamics of the main determinants of $\mathrm{CO}_{2}$ emissions (see Inomata and Owen (2014) and Owen et al. (2016) for a comparison of the different MRIO databases).

The WIOD's WIOTs are expressed in current millions of United States dollars. As a first step, we transform WIOTs into constant 1995 dollars using tables of current and previous year prices from WIOD. We then apply the GRAS ${ }^{3}$ to balance them (Junius and Oosterhaven, 2003; Lenzen et al., 2007; Temurshoev et al., 2013). Thus, an environmentally-extended MRIO model can be estimated on the basis of this information.

$$
\mathbf{x}=\mathbf{A x}+\mathbf{y}
$$

We let Equation 1 represent the equilibrium in this multiregional context, with $\mathrm{r}$ countries and n sectors, where $\mathbf{x}((r \times n) \times 1)$ denotes the total output, $\mathbf{A}((r \times n) x(r \times n))$ is

\footnotetext{
${ }^{2}$ We calculate carbon embodied in trade for the 41 areas in the WIOTs, but in the econometric estimation we delete Taiwan and the region "Rest of the World".

${ }^{3}$ This procedure is used to adjust a matrix, with a minimum loss of information, to a required sum of columns and rows when positive and negative entries are present.
} 
the matrix of multiregional technical coefficients, with each of its representative elements $a_{i j}^{r s}$ indicating the volume of intermediate input $i$ of a country $r$ necessary to produce a unit of output $j$ in country $s$, and $\mathbf{y}((r \times n) \times 1)$ is the vector of total final demand of countries. This equation can be also represented in terms of the well-known Leontief inverse $\mathbf{L}((r x n) x(r x n))$ defined for the whole multiregional economy

$$
\mathbf{x}=(\mathbf{I}-\mathbf{A})^{-1} \mathbf{y}=\mathbf{L y}
$$

Pre-multiplying this equation by a diagonalised vector of direct emissions intensities (direct $\mathrm{CO}_{2}$ emissions per unit of output) and considering the breakdown of final demands according to their sector-country final allocation, we obtain, as in Cazcarro et al. (2012) matrix $\mathbf{C}((r \times n) x(r x n))$ :

$$
\begin{aligned}
& \mathrm{C}=\left(\begin{array}{ccccc}
\mathrm{C}_{11} & \mathrm{C}_{12} & \cdot & \cdot & \mathrm{C}_{1 \mathrm{r}} \\
\mathrm{C}_{21} & \mathrm{C}_{22} & \cdot & \cdot & \mathrm{C}_{2 \mathrm{r}} \\
\cdot & \cdot & \cdot & \cdot & \cdot \\
\mathrm{C}_{\mathrm{s} 1} & \cdot & \mathrm{C}_{\mathrm{ss}} & \cdot & \mathrm{C}_{\mathrm{sr}} \\
\cdot & \cdot & \cdot & \cdot & \cdot \\
\mathrm{C}_{\mathrm{r} 1} & \mathrm{C}_{\mathrm{r} 2} & \cdot & \cdot & \mathrm{C}_{\mathrm{rr}}
\end{array}\right)=
\end{aligned}
$$

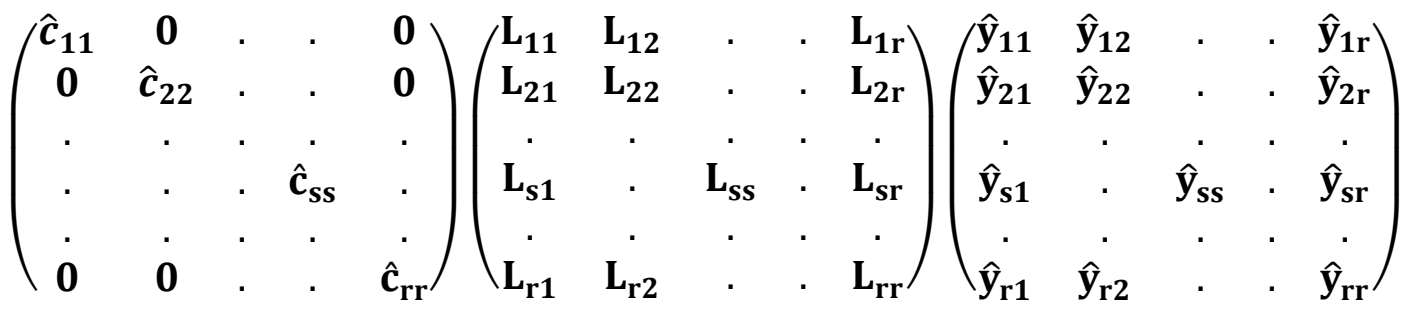

Here $\mathbf{C}$ captures all $\mathrm{CO}_{2}$ flows in the global economy associated with the production of commodities traded among countries, as well as for each country's domestic consumption. Matrix $\mathbf{C}$ is composed of block matrices $\left(\mathbf{C}_{\mathbf{r s}}\right)(n \times n)$, where each element $c_{r s}^{i j}$ depicts the $\mathrm{CO}_{2}$ emissions generated in sector $i$ of region $r$ to meet the final demand of sector $j$ in region $s$.

Summing by rows in $\mathbf{C}$ and defining $\mathbf{e}(n \times 1)$ as a vector of ones, we obtain the total $\mathrm{CO}_{2}$ emitted as a result of production in country $s$ as follows:

$$
\mathbf{C O 2}_{\mathbf{s}}=\sum_{r} \mathbf{e}^{\prime} \mathbf{C}_{\mathrm{sr}} \mathbf{e}=\mathbf{e}^{\prime} \mathbf{C}_{\mathrm{ss}} \mathbf{e}+\sum_{r \neq s} \mathbf{e}^{\prime} \mathbf{C}_{\mathrm{sr}} \mathbf{e}
$$

Therefore, we get two components. The first, $\mathbf{e}^{\prime} \mathbf{C}_{\mathbf{s s}} \mathbf{e}$, is the domestic factor reflecting all the $\mathrm{CO}_{2}$ emitted in country $s$ to meet its own internal demand. The second component $\left(\sum_{r \neq s} \mathbf{e}^{\prime} \mathbf{C}_{s r} \mathbf{e}\right.$ ) is the $\mathrm{CO}_{2}$ generated in country $s$ and embodied in the production of all the 
inputs needed to meet the final demand of the rest of the regions. Note that for each bilateral flow $\mathbf{e}^{\prime} \mathbf{C}_{s r} \mathbf{e}$, later called $\mathrm{CO}_{s r}$ and introduced in Equation 5 as a dependent variable, synthetizes all the structural, technological, market, and institutional conditions underlying the trade relationships between countries and the associated flows of $\mathrm{CO}_{2}$ embodied. In this regard, we can link the final demand of a country to the associated impact on other countries through the international supply chain. The use of emissions embodied in exports as the dependent variable in the trade gravity model is one of the main contributions of this paper. Whereas trade gravity models have traditionally assessed the factors driving changes in gross trade (and subsequently $\mathrm{CO}_{2}$ emissions related to gross flows), using $\mathrm{CO}_{s r}$ enables tracing them through the entire supply chain, thus accounting for all the emissions generated and incorporated through trade in global value chains.

The next step involves identifying the relevant variables potentially driving emissions embodied in trade. As is commonly shown in the input-output literature, the growing demand for final goods and services is key in explaining emissions embodied in trade. This demand effect is a compound often affected by the economic capacity of the buyer/final consumer, primarily explained by changes in both GDP per capita and population. Besides, emissions can be mediated by other factors not explicitly considered in the input-output information that still crucially affect demand, trade structure, and, to some extent, the degree of specialization of countries. This is especially the case of transport and other transactions costs, as well as any differential barriers to trade across counties. In this regard, there is robust evidence that, whereas distance hampers international trade (Disdier and Head, 2008; Head and Mayer, 2013), institutional agreements boost it (Kohl and Trojanowska, 2015; Kohl, 2014). Moreover, the total emission intensities of goods traded are affected by the differing technological options of countries (which are mainly captured by the $\mathbf{c}$ and $\mathbf{L}$ components of the input-output model). In this regard, the country energy mix, or more general environmental aspects (environmental awareness of citizens, environmental reserves, restrictive/lax environmental regulations), are variables that potentially explain the differences observed in these components. Finally, international agreements on climate change and emissions reduction, and their potential effects on signing countries should also be considered. The scientific literature on this issue has found that trade agreements with environmental provisions contribute to the decrease of $\mathrm{CO}_{2}$ emissions (Baghdadi et al., 2013) and those 
countries that signed the Kyoto protocol tended to reduce their emissions (Grunewald and Martinez-Zarzoso, 2016).

In this context, the main determinants underlying $\mathrm{CO}_{2}$ bilateral trade flows are econometrically estimated using a trade gravity model. Since the seminal paper of Tinbergen (1962), trade gravity models have been traditionally used to investigate the main driving forces of trade. Subsequently, important initial studies of trade gravity theory were developed by Anderson (1979) and Bergstrand (1985). However, and despite the substantial theoretical and empirical contributions, the studies in the field spread from the late 1990s with significant work by Eaton and Kortum (2002) and Anderson and van Wincoop (2003). The empirical validations of the gravity equation (Evenett and Keller, 2002; Helpman, 1987; Hummels and Levinsohn, 1995), conclude its compatibility with the main theoretical models to explain international trade, including, in a complementary fashion, the Heckscher-Ohlin models with specialization, and the models of the New International Trade Theory with increasing returns and monopolistic competition (Anderson, 1979; Anderson and van Wincoop, 2003; Deardorff, 1984; Helpman and Krugman, 1985). As the main advantages of these models, we highlight their explanatory power regarding bilateral trade flows and the stability of the results obtained. Initially, trade gravity equations were applied to cross-section data, but they have been increasingly applied to panel data (Baier and Bergstrand, 2007; Bergstrand et al., 2015; Cirera et al., 2015; Egger and Nelson, 2010; Head et al., 2010). During the last decade, a large number of studies (Anderson and van Wincoop, 2003; Baier and Bergstrand, 2009; Olivero and Yotov, 2012) have examined the treatment of multilateral resistance terms (MRT), the endogeneity of trade policies (Baier and Bergstrand, 2007; Egger and Nigai, 2015; Kohl, 2014), and the problem of zero trade flows (Head and Mayer, 2014; Santos-Silva and Tenreyro, 2006).

The specification of the equation used herein follows the work of Bergstrand (1989), Feenstra et al. (2001), and Anderson and van Wincoop (2003):

$$
\begin{aligned}
& C O 2_{s r t}=\beta_{1} \ln \left(\text { POP }_{s t}\right)+\beta_{2} \ln \left(\text { POP }_{r t}\right)+\beta_{3} \ln \left(G D P p c_{s t}\right)+\beta_{4} \ln \left(G D P p c_{r t}\right)+ \\
& \beta_{5} \ln \left(\text { DISTANCE }_{s r}\right)+\beta_{6} \text { CONTIGUITY }_{s r}+\beta_{7} \text { BOTHIN }_{\text {srt }}+\beta_{8} \text { RTA }_{\text {srt }}+ \\
& \beta_{9} \ln \left(\text { ENERGY }_{s t}\right)+\beta_{10} \ln \left(\text { ENERGY }_{r t}\right)+\beta_{12} \text { Kyoto }_{\text {srt }}+u_{s r t}
\end{aligned}
$$

Where, as previously, $s$ and $r$ are the exporting and importing countries, respectively, and $t$ expresses the year. As before, $\mathrm{CO}_{2 r t}$ is the flow of $\mathrm{CO}_{2}$ embodied in exports from $s$ to 
$r$ in year $t$ expressed in kilotons/year. $\mathrm{CO}_{2}$ emissions embodied in bilateral exports are estimated using input-output tables for each year from 1995 to 2009, yielding 22,230 observations. Table 1 summarises the main descriptive statistics for the variables in the model.

\section{Insert Table 1}

We include a set of regressors that control for the economic, commercial, institutional, and energy factors of each pair of countries. First, the population $(P O P)$ of the commercial partners is introduced in the model (in logarithms) to control for the scale of countries. Similarly, in an attempt to evaluate the effect that development exerts on $\mathrm{CO}_{2}$ emissions embodied in trade, we include gross domestic product per capita (measured in constant 2005 US\$ and also in logarithms) of the exporter and importer countries (GDPpc). Demographic and economic data are from the WorldBank (2016). Trade costs are proxied using the distance (in logarithms) in kilometers (DISTANCE) between the most populated cities of the exporter and importer countries (c.f., Mayer and Zignago, 2011). Additionally, we control for the influence of having a common border (CONTIGUITY).

As can be seen in Equation 5, the model also controls for many institutional arrangements affecting trade. The variable BOTHIN represents accession of the trading pair to the World Trade Organization (WTO), taking the value of 1 if both countries are members of WTO in year $t$, respectively, and 0 otherwise. RTA accounts for regional trade agreements between the trade partners, taking the value of 1 if both countries belong to the same agreement in every year, and 0 otherwise (de Sousa, 2012).

Since energy consumption notably influences the trends of $\mathrm{CO}_{2}$ emissions (IPCC, 2014), data on energy use per capita for each pair of countries have been included ( $E N E R G Y)$. These variables are logged, depicting the energy use in kg-of-oil equivalent per capita (World Bank, 2016). To account for the impact of international climatic change and emissions reduction agreements, we include a dummy controlling for the entry into the Kyoto Protocol of both commercial partners (Kyoto) and equals 1 when the protocol was implemented in both countries.

As Anderson and van Wincoop (2003) and Baldwin and Taglioni (2006) point out, omitting relevant variables can generate biased estimates. We follow the suggestion of Baier and Bergstrand (2007) and Egger and Nelson (2010) to capture MRT effects in 
panel data by using country-time fixed effects effects $\left(\delta_{s t}\right.$ and $\left.\delta_{r t}\right)$. These capture the characteristics of the exporting and importing countries that are not controlled via only time-sensitive variables in the model. We also implement Baier and Bergstrand (2007) proposed solution of including pairwise fixed effects to control for endogeneity induced by commercial agreements. This applies to all the institutional variables in our model, i.e., RTA, BOTHIN and Kyoto.

To model Equation 5, we estimated using the Poisson pseudo-maximum likelihood (PPML) approach (Santos-Silva and Tenreyro 2006; 2010). According to Yotov et al. (2016), this method is preferred when estimating gravity equations for four reasons. First, it is robust to heteroskedasticity, which is inherent to trade data (SantosSilva and Tenreyro, 2006). Second, it is compatible with the existence of zero bilateral trade flows (Head and Mayer, 2014). Third, it ensures that the fixed effects match with their structural terms (Arvis and Shepherd, 2013; Fally, 2015). And, fourth, its estimators are consistent with the theoretical general equilibrium effects (Anderson et al., 2015). Following Head and Mayer (2014) and Yotov et al. (2016), we then checked robustness of the resulting gravity equation by also estimating it via ordinary least squares (OLS). ${ }^{4}$

In sum, we estimate alternative specifications to be able to measure the effect of such country-time-specific factors as income, population, and energy use (models 1 and 2 in Tables 2 and 3) but also to control for MRT (models 3, 4, and 5 in Tables 2 and 3) and endogeneity issues regarding the institutional determinants (model 5 in Tables 2 and 3). These specifications are estimated using OLS (models 1 and 3 in Table 2) and PPML (models 2, 4 and 5 in Table 2). In an attempt to discern specific regional patterns, these models have been obtained for the three groups of countries defined in the Kyoto Protocol (see the results section and the supplementary information for more details on this classification).

\section{Results and discussion}

\subsection{Trends in $\mathrm{CO}_{2}$ emissions trade: 1995-2009}

From 1995 to 2009, international exchanges that embodied $\mathrm{CO}_{2}$ emissions tended to grow. Indeed, they grew at an average of almost 3\% yearly (see Figure 1). Despite this, $\mathrm{CO}_{2}$ embodied in exports worldwide remained quite stable up to 2001; subsequently

\footnotetext{
${ }^{4}$ Note that when estimating using PPML, the dependent variable $\left(\mathrm{CO}_{\text {srt }}\right)$ is defined in levels. But it is expressed in logarithms when using OLS as the estimation technique.
} 
increased by an average of $7.4 \%$ annually up to 2008 , and then dropped as a result of the global economic crisis.

On average, during the period 1995-2001, embodied carbon trade from China, high-income EU countries, North America, and Russia, represented 21\%, 20\%, 15\% and $11 \%$ of total $\mathrm{CO}_{2}$ exports, respectively (see Figure 1). At that juncture China became a member of the WTO. Its trade grew rapidly, and as a result $\mathrm{CO}_{2}$ exports started to grow at an average annual rate of $18.4 \%$. So by 2009 it accounted for $46 \%$ of global $\mathrm{CO}_{2}$ exports. As a result, $\mathrm{CO}_{2}$ embodied in exports of high-income EU and Russia lost shares in total $\mathrm{CO}_{2}$ exchanges although they too continued to grow, albeit at more modest average annual rates of $2 \%$ and $1 \%$, respectively. Declines in the export of $\mathrm{CO}_{2}$ emissions from North America were both relative and absolute; they produced 5\% of total global $\mathrm{CO}_{2}$ emissions in 2005 and decreased their emissions at an annual average of $2 \%$ between 2001 and 2008.

Figure 1: $\mathrm{CO}_{2}$ emissions embodied in exports by world regions, 1995-2009.

\section{Insert figure 1 here}

Source: own elaboration from WIOD (2012) and Genty et al. (2012). ACM: Australia, Canada and Mexico, BRIIT: Brazil, Russia, India, Indonesia and Turkey, East Asia: North Korea and Japan, EU: European Union, USA: United States and CHN: China.

MRIO models identify the responsibilities for production and consumption activities through global supply chains. That is, they can be powerful tools in allocating GHG responsibilities and for studying economic and environmental linkages among countries. With this in mind, our findings suggest that the great rise in Chinese $\mathrm{CO}_{2}$ emissions embodied in exports between 1995 and 2009 (around 1.7 million kilotons) was, largely related to changes in U.S. final demand (see Figure 2). Around 63\% of China's export rises during this period were devoted to the growing consumption and investment activities in the U.S. that simultaneously tended to externalize $\mathrm{CO}_{2}$-intensive industries during these years (see Figures 2 and SI1). In 1995, 33\% of the $\mathrm{CO}_{2}$ emissions embodied in Chinese exports were destined for the U.S.; by 2009 this figure reached 56\%. Japan and Germany were also responsible for a significant part of the rise in Chinese $\mathrm{CO}_{2}$ emissions, but their shares tended to decrease from 1995 to 2009. Japan’s share fell from $21 \%$ to $7 \%$, while Germany’s share decreased from $8 \%$ to $5 \%$.

Figure 2: $\mathrm{CO}_{2}$ emissions embodied in Chinese bilateral exports by destination, 
1995-2009.

Insert figure 2 here

Source: own elaboration from WIOD (2012) and Genty et al. (2012). ACM: Australia, Canada and Mexico, BRIIT: Brazil, Russia, India, Indonesia and Turkey, East Asia: North Korea and Japan, EU: European Union and USA: United States.

Other countries (Figure SI1) follow two different patterns. In areas such as BRIIT, East Asia, and certain European countries, including Germany, $\mathrm{CO}_{2}$ emissions embodied in exports rose considerably. Again, final demand in the U.S. was largely responsible for the increase in $\mathrm{CO}_{2}$ emissions embodied in the exports of these countries. But Canada, Spain, China, and Great Britain also played significant roles in their $\mathrm{CO}_{2}$ exports. Then there are the US and Russia which, on balance, tended to reduce exports of $\mathrm{CO}_{2}$ emissions from 1995 to 2009. Reductions in U.S. embodied $\mathrm{CO}_{2}$ were experienced through exports to Japan, Canada, Mexico and Germany. Russia mostly reduced the $\mathrm{CO}_{2}$ content of its exports via trade with Germany, Italy, Japan and Canada.

\subsection{Factors that explain $\mathrm{CO}_{2}$ embodied in bilateral trade flows}

Given the broad trends in $\mathrm{CO}_{2}$ emissions embodied in trade flows, we now present the trade equation to quantify the role of each explanatory factor in the $\mathrm{CO}_{2}$ embodied in bilateral trade flows between 1995 and 2009. Table 2 shows the estimated results of the alternative models. Subsequently, we re-estimate them for the three groups of countries discussed above.

The estimated coefficients of population show positive and significant sign, both for the exporter and importer areas, being compatible with the traditional positive and important scale effects from MRIO models (Table 2). In a context of increasingly sophisticated demand patterns, countries tend to have markets that produce a greater variety of products, as important exporters of differentiated products (Krugman, 1980). The literature shows that, from the 1970s, manufactured products appear to follow the former commercial pattern, with primary goods being less likely to follow this path (Serrano and Pinilla, 2012). Therefore, the development of industries specialised in differentiated products intensive in carbon content, mainly in countries with large domestic markets, would boost the increase in exchanges of embodied $\mathrm{CO}_{2}$ emissions. This result of population is not specific to the trade in emissions, but is a common result in works that use gravity models to explain international trade.

Table 2 here 
We relate the level of development of countries to $\mathrm{CO}_{2}$ emissions embodied in trade using GDP per capita. The exporter's GDP per capita takes a statistically significant negative sign, which means that as the income per inhabitant of the exporter grows, the level of $\mathrm{CO}_{2}$ emissions embodied in its exports falls (see Table 2). This is related to the environmentally sensitivity and higher technological level of countries in more-advanced stages of development. The latter typically entails improved energy efficiency and investment in cleaner technologies (Gales et al., 2007). Contrarily, the coefficient for income elasticity is statistically significant and positive for importing countries, which suggests that as the average incomes of people in those countries rise so do their imports of emissions-intensive products. In other words, as income rises, economies depend more on foreign emissions, which suggests displacement of $\mathrm{CO}_{2}$ loads, which tend to be embodied in the electricity, metals, minerals, and transport sectors. Such results have been obtained in prior literature (Cole, 2004b; Muradian et al., 2002; Peters and Hertwich, 2008) and are also compatible with the stylized facts described in the preceding section on the basis of the MRIO estimations. Thus, signs and statistical significance of both coefficients show that the PHH holds true; that is, it can be said that the level of economic development is indirectly related to the export of emissions and directly related to the import of emissions. That is, it confirms naïve observations that $\mathrm{CO}_{2}$ embodied in exports moderated in the high-income EU economies, North America, and the U.S. Imports by high-income countries, such as the U.S., Japan, and Germany boosted Chinese emissions. These countries tended to import manufactured products (Serrano and Pinilla, 2012), which have high income elasticities compared to primary products, and usually embody large volumes of emissions.

The geographical control variables used in gravity models of international trade are statistically significant with expected signs (see Table 2). That is, distance negatively affects international trade and, therefore, $\mathrm{CO}_{2}$ exchanges. This can be explained by higher costs associated with freight transport, including all carrying costs. A common border between countries boosts emissions embodied in trade, i.e., exchanges of emissions are more intense between adjacent countries, even after accounting for distance. So both distance and contiguity play a role when evaluating carbon-embodied trade. In this regard, Johnson and Noguera (2012) and Noguera (2012) find a negative and significant relationship between distance and trade which is stronger for gross exports than for value added exports, given the fragmentation of production processes. 
To test for differences in carbon trade, we model both total $\mathrm{CO}_{2}$ embodied in exports (Table 2) and just direct $\mathrm{CO}_{2}$ in exports (Table SI1). Not surprisingly, since it is an obstacle to trade in general, both approaches reveal that distance is an obstacle to $\mathrm{CO}_{2}$ exchange-statistically significant with a negative sign. Interestingly, distance's effect is about $20 \%$ to $40 \%$ larger for direct $\mathrm{CO}_{2}$ trade flows than for total embodied $\mathrm{CO}_{2}$. So the complexity of global value chains (accounted for by embodied carbon trade) leads to important variations in the relationship between carbon trade and geography. That is, when we consider not only the carbon directly traded by means of gross exports but also indirectly through exchanges of intermediates in global supply chains, the role of geography and transport costs diminishes. These results are in line with those of Noguera (2012, p.2), who states that "bilateral trade cost elasticity of value added exports is around two-thirds of that for gross exports”, reflecting the importance of bilateral trade costs and costs with third countries. ${ }^{5}$

As Table 2 shows (models 1 and 2), ceteris paribus, the higher the energy use per capita of the exporting country, the higher are the $\mathrm{CO}_{2}$ emissions embodied in its exports. This is logical, given that emissions embodied in exports computed in the MRIO capture the intensity of emissions of countries and the contribution of the energy sectors to production. This variable controls for whether the $\mathrm{CO}_{2}$ intensity of exports is influenced by the country's overall energy intensity, and thus, presumably, also the $\mathrm{CO}_{2}$ intensity of the whole economy. This relationship is also found for importing countries, albeit with lesser effects (see model 2 in Table 2). Finally, looking at model 5 in which the endogeneity of trade policy is treated via pair fixed effects, regional trade agreements (RTAs) foster trade between countries by reducing tariffs and easing commercial exchanges, and thereby boosting the export of $\mathrm{CO}_{2}$-intense goods $\mathrm{A}$ large body of literature suggests that bilateral agreements substantially boost trade (e.g., Baldwin, 2006; Bhagwati et al., 1999). Still, this aspect of our results differs from that of Baghdadi et al. (2013), who find an inverse relationship between RTAs with environmental provisions (mostly in developed countries) and $\mathrm{CO}_{2}$ emissions. ${ }^{6}$ Finally, looking at model 5 (with endogeneity considered), mutual participation in the Kyoto Protocol of trade partners is associated with lower emissions embodied in exports. This raises the spectre that

\footnotetext{
${ }^{5}$ The larger importance of distance when measuring direct compared to embodied (direct and indirect) carbon trade is also shown in Table SI2, where the partial $R^{2}$ are calculated using simple regressions. In this case, the partial $R^{2}$ is 1.7 times larger when direct carbon trade is the dependent variable, which shows the robustness of our findings.

${ }^{6}$ Note that, in this paper, RTAs do not consider environmental provisions.
} 
nonsignatory countries might specialize in producing and exporting goods heavily embodying $\mathrm{CO}_{2}$.

Having now gained a broad perspective from our findings, we turn to an analysis of the different groups of countries to identify specific patterns and to determine the robustness of our core findings. Following the Kyoto Protocol criteria, we classify exporting countries into Non-Annex 1 (NA1) countries, which are mostly developing nations; Annex 2 (A2) countries, which consist of developed OECD nations, and Economies in Transition (EIT). ${ }^{7}$ Separate results for these three groups are shown in Table 3. Note that when we examine the criteria used to compare the models estimated in Table 2, both the adjusted- $R^{2}$ and the RESET test indicate that model 5 is best. Still, we are not just interested in identifying the roles of institutional factors, but also of such other factors as population, energy use, and income (absorbed by the dummies), so we reestimate all specifications.

\section{Insert Table 3}

Findings in Table 3 related to the variables controlling for market scale (population) and the level of development of countries offer very interesting, complementary results. Those for population are robust since, as we noted previously, their coefficients are positive and statistically significant for every country group and the exporting and importing country. These regional samples also reinforce the $\mathrm{PHH}$ and our broader findings on the effect of the level of economic development on the carbon content of exports. The coefficient of GDP per capita of the exporting nations is negative and statistically significant for all but A2 countries, which suggests that an increase in income of a nation is more apt to reduce the amount of carbon embodied in its exports for developing economies and those in transition. Since developed nations have already incorporated clean technologies and have already experienced significant structural change (much by enabling PHH via environmental regulation), they have less capacity to reduce the amount of carbon embodied in their exports. This explanation is further reinforced by the larger coefficient for NA1 countries compared to that for EITs. The difference in magnitude of the elasticity size across the three samples has important implications, as it suggests developing countries are more able to reduce global $\mathrm{CO}_{2}$ emissions via technological improvements and structural changes. That is, there is a sort

\footnotetext{
${ }^{7}$ See supplementary information for more detail on country classifications.
} 
of “diminishing” global environmental benefit as economies become richer (all other factors being constant).

On the other hand, the coefficient of GDP per capita of the importing nations remains statistically significant and positive across the three region types (A2, NA1 and EITs). This suggests a direct relationship between a nation's income and the amount of $\mathrm{CO}_{2}$ embodied in its demand for internationally supplied goods. But the size of the coefficient is much higher for NA1 countries than for A2, and particularly EIT countries (see Table 3). These findings are confirmed via OLS and PPML estimates. More specifically, they show that the effect of rises in income per capita for importing nations enables increases in the amount of carbon embodied in exports that are on the order of 24\% higher for developing countries compared to developed nations (models NA1-2 and A2-2 in Table 3). This suggests that, as economies strengthen, they tend to incorporate more $\mathrm{CO}_{2}$ emissions through international trade (related to increasing foreign demands for such inputs as electricity, minerals, metals, and use of transport that embody large volumes of $\mathrm{CO}_{2}$ ). In other words, developed nations tend to externalize environmental pressures by "offshoring” production to developing countries, once again supporting the PHH. This points not only to rising global market shares of developing economies, but also to the different technological conditions of exporting countries, with high-income areas generating comparatively less $\mathrm{CO}_{2}$ per unit of output, i.e., producing in a more efficient way or retaining the production of those commodities they can produce more efficiently than can developing nations. It is important to note that the share of total national production in service sectors tends to be larger in developed countries; whereas in developing regions, manufacturing industries tend to have larger shares of total national production. This is important since manufacturing tends to generate far more $\mathrm{CO}_{2}$ emissions. As for economies in transition (EITs), the positive but lesser impact of this variable is related to the moderation in their intensity of production and their growing internationalization between 1995 and 2009, when most of these countries started their transitions toward market economies.

Similarly, distance (a proxy for the costs of trade) is negative for all country groups, but its effect increases as the income level of the exporter falls; this aspect of distance's effect is particularly intense for EITs. In these regions, $\mathrm{CO}_{2}$ emissions embodied in exports fall rather rapidly with rises in distance. This can be rationalized through the types of goods that EITs export. On the whole, developed countries export 
high value-added products and, as a consequence, transport costs (proxied as distance) comprise a small share of final prices. The opposite happens with commodities exported by developing areas, for example textiles. In this line, sharing a border also boosts emissions embodied in exports, but the effect is more significant for EITs-economies that experienced extreme trade integration during the period of analysis.

The elasticities for energy use per capita of exporting countries on $\mathrm{CO}_{2}$ emissions embodied in exports are statistically significant, positive and particularly large for EITs and NA1 countries. While statistically significant and positive, the size of this elasticity is substantially moderated in the case of developed economies. This suggests that overall energy intensity of an economy proxies for its general reliance on manufacturing and its kind of industrial specialization. That is, it indicates that developing countries (NA1) and economies in transition (EITs) are more apt to export energy-intensive products, which boosts the $\mathrm{CO}_{2}$ emissions embodied in their exports. But, in the case of developed countries, the subdued impact of this variable likely relates the extent to which they “export” polluting activities, given their more stringent environmental regulation and rising incentives to implement clean technologies, which reduce energy intensity. Moreover, the coefficient of the energy use of importing nations shows its impact is statistically significant, positive and robust for the goods coming from EITs (see Table 3). Consequently, as importing nations become domestically energy-intensive, they simultaneously tend to increase the $\mathrm{CO}_{2}$ embodied in imports from EITs. This can be explained by the rising participation of these economies in global supply chains as producers, exporters, and also importers of $\mathrm{CO}_{2}$-intensive goods and services.

Moving to the institutional factors, we consider the estimates in which MRT and endogeneity of policies are addressed (model 5 in Table 3). The effect of RTAs on $\mathrm{CO}_{2}$ emissions is robust and positive; nevertheless, it is not statistically significant in the case of NA1 countries, which are often not party to such agreements. Moreover, RTAs have a different capacity to promote international trade between partners, mainly because of their heterogeneity (Jean and Bureau, 2016; Serrano and Pinilla, 2016). As can be seen, RTAs that affect developed nations have the largest impact on $\mathrm{CO}_{2}$, as they are nations that have historically benefited most from such commitments. EITs ratified the Central European Free Trade Agreement in 1992, after the end of the Council for Mutual Economic Assistance (COMECON) in 1991. Its capacity to boost international trade is more moderate (plus some of these countries left this organization to join the European Union 
in 2004). Membership in the WTO yields three different patterns. It has no statistically significant effect for EITs. But if the exporting nation is a WTO-member NA1 country, lower amounts of $\mathrm{CO}_{2}$ are clearly embodied in its exports compared to those of nonmember NA1 countries. Finally, developed nations display a statistically significant effect that is both large and positive (see Table 3 models 5).

Note that WTO agreements mostly boost trade in manufacturing and services (primary products benefit less), and moreover that services were included only after 2000 with the General Agreement on Trade in Services (GATS). In this regard, the most developed areas tend to export differentiated goods and services commonly associated with the late stages in global supply chains and which, therefore, embody large volumes of $\mathrm{CO}_{2}$ emissions. Eventually, the ratification of the Kyoto Protocol by trade partners reduces the amount of carbon embodied in trade if the exporter is an NA1 or A2 country, with the effect slightly more intense for the former. The effect of ratifying the Kyoto Protocol is not statistically significant for EITs. These findings are in line with recent environmental literature that studies the impact of the Kyoto Protocol on $\mathrm{CO}_{2}$ emissions (e.g., Grunewald and Martinez-Zarzoso, 2016, find that direct $\mathrm{CO}_{2}$ emissions declined in those countries that signed the protocol, and Aichele and Felbermayr, 2015, observe an increase in the carbon content of imports).

\section{Conclusions}

This paper proposes a combined MRIO-gravity approach to analyze the determinants of the carbon trade in global value chains. It is novel in its focus on the role that trade and its main explanatory factors have played in the generation of global $\mathrm{CO}_{2}$ emissions. Our models acknowledge the multisectoral character of economies, the increasing globalization of supply chains, and the need for flexible models to explain the countryspecific factors and environmental variables underlying the $\mathrm{CO}_{2}$ emissions embodied in trade.

After obtaining $\mathrm{CO}_{2}$ emissions embodied in bilateral exports using an MRIO model, we estimate the main determinants of these trends using panel data econometrics. We analyze the carbon embodied in bilateral trade flows among 39 countries from 1995 to 2009. To the best of our knowledge, this is the very first attempt to combine multiregional input-output modelling and panel data econometrics to study carbon embodied in trade. Our findings show that $\mathrm{CO}_{2}$ emissions embodied in bilateral trade 
increased from 1995 to 2009 at the global level. We also find important divergences among countries, with countries such as the U.S. and Russia displacing their pollution by importing growing volumes of $\mathrm{CO}_{2}$ from other regions, such as China, India and Indonesia. Population and the level of development are two of the main contributors to $\mathrm{CO}_{2}$ displacement.

In general, our work highlights the positive and negative income elasticity of $\mathrm{CO}_{2}$ emissions for demand and supply, respectively. Our results show that as economies grow, they tend to externalize $\mathrm{CO}_{2}$ emissions, which are mainly embodied in imports from developing countries. Nevertheless, in their role of exporters, they tend to shift exports to less intensive $\mathrm{CO}_{2}$ goods and to introduce cleaner technologies. All in all, the signs and sizes of statistically significant coefficients associated with all these variables support the Pollution Haven Hypothesis (PHH) and the role that technologies play in reducing global emissions. Additionally, the overall energy intensity of countries is important, as it proxies for sectoral composition of production and energy dependence. Moreover, other variables that affect trade, like transport costs and trade agreements, are important in understanding the increase in $\mathrm{CO}_{2}$ emissions embodied in international trade; but they yield different effects depending on the country's level of economic development. Finally, the Kyoto agreements tended to reduce the $\mathrm{CO}_{2}$ emissions embodied in exports of developing and developed countries that participated in the protocols.

Accordingly, some implications can be derived from the results in this paper. First, they reveal the potential complexity of any strategies that be used to mitigate climate change arising from trade. In this regard, both the demand and supply side, and their determinants (population and economic growth, energy dependence), are important in explaining global emissions embodied in trade. Second, our results confirm the effects that different technological and growth levels of countries and the specialization patterns in their economies can have on global emissions. Additionally, as might be expected, elasticities diverge across world regions. This suggests a need to evaluate the potential differential effects of mitigation strategies when developing paths towards sustainable societies. Our results also show that individual country characteristics, geographical distance, regional agreements, institutional factors, and other unobserved factors (such as social awareness of environmental problems) matter when defining cleaner trade relationships. Hence, this study of anthropogenic relationships may offer key information for the formulation of scenarios of global economic and environmental change. 
Finally, this paper contributes to the literature in two additional ways. First, our approach links two methods that have traditionally competed; in so doing, we exploit their synergies. Second, our work complements existing quantifications of $\mathrm{CO}_{2}$ embodied in trade and further verifies the PHH. Thus, the paper develops a complementary tool to assess the primary determinants of carbon displacements, to identify different regional behaviors, and to examine the sensitivity of global emissions to temporal change. It therefore presents a new and promising line of research, and opens a path for future work using different MRIO databases. The approach allows researchers to evaluate the consistency of the results, while also offering ways to study how different production technologies, as depicted in international MRIO models, influence $\mathrm{CO}_{2}$ emissions and other environmental features.

\section{References}

Aichele, R. and G. Felbermayr (2015) Kyoto and Carbon Leakage: An Empirical Analysis of the Carbon Content of Bilateral Trade. Review of Economics and Statistics, 97, 104-115

Alcamo, J. (2008) Environmental Futures: The Practice of Environmental Scenario Analysis (Developments in Integrated Environmental Assessment) (J. Alcamo, Ed.). Kassel, Elsevier Science

Alcamo, J., A. Bouwman, J. Edmonds, A. Grabler, T. Morita and A. Sugandhy (1995) An Evaluation of the IPCC IS92 Emission Scenarios. In Climate Change 1994, Radiative Forcing of Climate Change and An Evaluation of the IPCC IS92 Emission Scenarios (pp. 233-304). Cambridge, Cambridge University Press

Anderson, J.E. (1979) A Theoretical Foundation for the Gravity Equation. The American Economic Review, 69, 106-116

Anderson, J.E., M. Larch and Y. Yotov (2015) Estimating General Equilibrium Trade Policy Effects: GE PPML. CESifo Working Paper Series, 5592

Anderson, J.E. and E. van Wincoop (2003) Gravity with Gravitas: A Solution to the Border Puzzle. American Economic Review, 93, 170-192

Andrew, R.M. and G.P. Peters (2013) A multi-region input-output table based on the GlobalTrade Analysis Project database (GTAP-MRIO). Economic Systems Research, 25, 99-121 
Arvis, J.F. and B. Shepherd (2013) The Poisson quasi-maximum likelihood estimator: a solution to the "adding up" problem in gravity models. Applied Economics Letters, 20, 515-519

Baghdadi, L., I. Martinez-Zarzoso and H. Zitouna (2013) Are RTA agreements with environmental provisions reducing emissions? Journal of International Economics, 90, 378-390

Baier, S.L. and J.H. Bergstrand (2007) Do free trade agreements actually increase members' international trade? Journal of International Economics, 71, 72-95

Baier, S.L. and J.H. Bergstrand (2009) Estimating the effects of free trade agreements on international trade flows using matching econometrics. Journal of International Economics, 77, 63-76

Baldwin, R. and D. Taglioni (2006) Gravity for Dummies and Dummies for Gravity Equations. National Bureau of Economic Research Working Paper Series, No. 12516

Baldwin, R.E. (2006) Multilateralising Regionalism: Spaghetti Bowls as Building Blocs on the Path to Global Free Trade. World Economy, 29, 1451-1518

Bergstrand, J.H. (1985) The Gravity Equation in International Trade: Some Microeconomic Foundations and Empirical Evidence. The Review of Economics and Statistics, 67, 474-481

Bergstrand, J.H. (1989) The Generalized Gravity Equation, Monopolistic Competition, and the Factor-Proportions Theory in International Trade. The Review of Economics and Statistics, 71, 143-153

Bergstrand, J.H., M. Larch and Y.V. Yotov (2015) Economic Integration Agreements, Border Effects, and Distance Elasticities in the Gravity Equation. European Economic Review, 78, 307-327

Bhagwati, J., A. Panagariya and P. Krishna (1999) Trading Blocs: Alternative Approaches to Analyzing Preferential Trade Agreements. Cambridge, The MIT Press

Caliendo, L. and F. Parro (2015) Estimates of the Trade and Welfare Effects of NAFTA. The Review of Economic Studies, 82, 1-44

Cazcarro, I., R. Duarte and J. Sánchez-Chóliz (2012) Water Flows in the Spanish Economy: Agri-Food Sectors, Trade and Households Diets in an Input-Output 
Framework. Environmental Science \& Technology, 46, 6530-6538

Chen, Z.M., G.Q. Chen and B. Chen (2010) Embodied Carbon Dioxide Emissions of the World Economy: A Systems Input-Output Simulation for 2004. Procedia Environmental Sciences, 2, 1827-1840

Cirera, X., F. Foliano and M. Gasiorek (2015) The impact of preferences on developing countries' exports to the European Union: bilateral gravity modelling at the product level. Empirical Economics, 50, 59-102

Cole, M.A. (2004a) Trade, the pollution haven hypothesis and the environmental Kuznets curve: examining the linkages. Ecological Economics, 48, 71-81

Cole, M.A. (2004b) US environmental load displacement: examining consumption, regulations and the role of NAFTA. Ecological Economics, 48, 439-450

Copeland, B. (2008) The Pollution Haven Hyphotesis.In K. P. Gallaghan (Ed.), Yearbook on Trade and the Environment (pp. 60-70). Cheltelham, Edward Elgar

Deardorff, A.V. (1984) Testing trade theories and predicting trade flows.In K. J. Arrow \& M. D. Intriligator (Eds.), Handbook of International Economics (Vol. 1, pp. 467517). Amsterdam, Elsevier

de Sousa, J. (2012) The currency union effect on trade is decreasing over time. Economics Letters, 117, 917-920

Dietzenbacher, E., B. Los, R. Stehrer, M. Timmer and G. de Vries (2013) The construction of world input-output tables in the WIOD project. Economic Systems Research, 25, 71-98

Disdier, A.C. and K. Head (2008) The Puzzling Persistence of the Distance Effect on Bilateral Trade. The Review of Economics and Statistics, 90, 37-48

Duarte, R. and H. Yang (2011) Input-output and water: introduction to the special issue. Economic Systems Research, 23, 341-351

Eaton, J. and S. Kortum (2002) Technology, Geography, and Trade. Econometrica, 70, $1741-1779$

Egger, P. and D. Nelson (2010) How Bad Is Antidumping? Evidence from Panel Data. Review of Economics and Statistics, 93, 1374-1390 
Egger, P.H. and S. Nigai (2015) Structural gravity with dummies only: Constrained ANOVA-type estimation of gravity models. Journal of International Economics, 97, 86-99

Evenett, S. and W. Keller (2002) On Theories Explaining the Success of the Gravity Equation. Journal of Political Economy, 110, 281-316

Fally, T. (2015) Structural gravity and fixed effects. Journal of International Economics, 97, 76-85

FCCC/CP/2015/L.9/Rev.1 Paris Agreement. (2016). United Nations Treaty Collection

Feenstra, R.C., J.A. Markusen and A.K. Rose (2001) Understanding the home market effect and the gravity equation: the role of differentiating goods. Working paper NBER (Vol. 6804). Cambridge

Gales, B., A. Kander, P. Malanima and M. Rubio (2007) North versus South: Energy transition and energy intensity in Europe over 200 years. European Review of Economic History, 11, 219-253

Genty, A., I. Arto and F. Neuwahl (2012) Final database of environmental satellite accounts: Technical report on their compilation. WIOD Deliverable 4.6

Grunewald, N. and I. Martinez-Zarzoso (2016) Did the Kyoto Protocol fail? An evaluation of the effect of the Kyoto Protocol on CO2 emissions. Environment and Development Economics, 21, 1-22

Guilhoto, J., J.M. Siroën and A. Yücer (2015) The Gravity Model, Global Value Chain and the Brazilian States. Working Papers DT/2015/02 DIAL (Développement, Institutions et Mondialisation). Paris

He, J. (2006) Pollution haven hypothesis and environmental impacts of foreign direct investment: The case of industrial emission of sulfur dioxide (SO2) in Chinese provinces. Ecological Economics, 60, 228-245

He, J. and J. Fu (2014) Carbon leakage in China's manufacturing trade: An empirical analysis based on the carbon embodied in trade. The Journal of International Trade \& Economic Development, 23, 329-360

Head, K. and T. Mayer (2013) What separates us? Sources of resistance to globalization. Canadian Journal of Economics/Revue Canadienne D’économique, 46, 1196-1231 
Head, K. and T. Mayer (2014) Gravity Equations: Workhorse,Toolkit, and Cookbook.In G. Gopinath, E. Helpman \& K. Rogoff (Eds.), Handbook of International Economics (Vol. 4, pp. 131-195). Amsterdam, Elsevier

Head, K., T. Mayer and J. Ries (2010) The erosion of colonial trade linkages after independence. Journal of International Economics, 81, 1-14

Helpman, E. (1987) Imperfect competition and international trade: Evidence from fourteen industrial countries. Journal of the Japanese and International Economies, 1, 62-81

Helpman, E. and P. Krugman (1985) Market Structure and Foreign Trade; Increasing Returns, Imperfect Competition, and the International Economy. Cambridge, MIT press

Hummels, D. and J. Levinsohn (1995) Monopolistic Competition and International Trade: Reconsidering the Evidence. The Quarterly Journal of Economics , 110, 799-836

Inomata, S. and A. Owen (2014) Comparative evaluation of MRIO databases. Economic Systems Research, 26, 239-244

IPCC (2014) Climate Change 2014: Impacts, Adaptation, and Vulnerability. Cambridge, Cambridge University Press

Jean, S. and J.C. Bureau (2016) Do regional trade agreements really boost trade? Evidence from agricultural products. Review of World Economics, 152, 477-499

Johnson, R.C. and G. Noguera (2012) Proximity and Production Fragmentation. American Economic Review, 102, 407-411

Johnson, R.C. and G. Noguera (2017) A Portrait of Trade in Value-Added over Four Decades. The Review of Economics and Statistics, 99, 896-911

Junius, T. and J. Oosterhaven (2003) The solution of updating or regionalizing a matrix with both positive and negative entries. Economic Systems Research, 15, 87-96

Kaya, Y. (1990) Impact of Carbon Dioxide Emission Control on GNP Growth: Interpretation of Proposed Scenarios. IPCC Energy and Industry Subgroup, Responses Strategies Working Group. Paris

Kohl, T. (2014) Do we really know that trade agreements increase trade? Review of World Economics (Weltwirtschaftliches Archiv), 150, 443-469 
Kohl, T. and S. Trojanowska (2015) Heterogeneous trade agreements, WTO membership and international trade: an analysis using matching econometrics. Applied Economics, 47, 3499-3509

Koźluk, T. and C. Timiliotis (2016) Do environmental policies affect global value chains? Paris, OECD Publishing

Lenzen, M., D. Moran, K. Kanemoto and A. Geschke (2013) Building Eora: a global multiregion input-output database at high country and sector resolution. Economic Systems Research, 25, 20-49

Lenzen, M., J. Murray, F. Sack and T. Wiedmann (2007) Shared producer and consumer responsibility - Theory and practice. Ecological Economics, 61, 27-42

Lenzen, M., R. Wood and B. Gallego (2007) Some comments on the GRAS method. Economic Systems Research, 19, 461-465

López, L.A., G. Arce and J.E. Zafrilla (2013) Parcelling virtual carbon in the pollution haven hypothesis. Energy Economics, 39, 177-186

Malik, A., J. Lan and M. Lenzen (2016) Trends in Global Greenhouse Gas Emissions from 1990 to 2010. Environmental Science \& Technology, 50, 4722-4730

Mayer, T. and S. Zignago (2011) Notes on CEPII's Distances Measures: The GeoDist Database. SSRN Electronic Journal, 25

Millimet, D.L. and J. Roy (2016) Empirical Tests of the Pollution Haven Hypothesis When Environmental Regulation is Endogenous. Journal of Applied Econometrics, 31, 652677

Munksgaard, J. and K.A. Pedersen (2001) CO2 accounts for open economies: producer or consumer responsibility? Energy Policy, 29, 327-334

Muradian, R., M. O’Connor and J. Martinez-Alier (2002) Embodied pollution in trade: estimating the "environmental load displacement" of industrialised countries. Ecological Economics, 41, 51-67

Nakano, S., A. Okamura, N. Sakurai, M. Suzuki, Y. Tojo and N. Yamano (2009) The Measurement of CO2 Embodiments in International TradeOECD Science, Technology and Industry Working Papers (Vol. 3). Paris, OECD Publishing

Noguera, G. (2012) Trade costs and gravity for gross and value added trade. Job Market 
Paper.

Olivero, M.P. and Y.V. Yotov (2012) Gravité dynamique : le cas où la taille du pays et l'accumulation d'actifs sont endogènes. Canadian Journal of Economics/Revue Canadienne D’économique, 45, 64-92

Owen, A., R. Wood, J. Barrett and A. Evans (2016) Explaining value chain differences in MRIO databases through structural path decomposition. Economic Systems Research, 28, 243-272

Peters, G.P. and E.G. Hertwich (2008) CO2 Embodied in International Trade with Implications for Global Climate Policy. Environmental Science \& Technology, 42, 1401-1407

Rahman, M.D.A., B. Los, A. Geschke, Y. Xiao, K. Kanemoto and M. Lenzen (2017) A flexible adaptation of the WIOD database in a virtual laboratory. Economic Systems Research, 29, 187-208

Sánchez-Chóliz, J. and R. Duarte (2004) CO2 emissions embodied in international trade: evidence for Spain. Energy Policy, 32, 1999-2005

Santos-Silva, J.M.C. and S. Tenreyro (2006) The Log of Gravity. Review of Economics and Statistics, 88, 641-658

Santos-Silva, J.M.C. and S. Tenreyro (2010) On the existence of the maximum likelihood estimates in Poisson regression. Economics Letters, 107, 310-312

Serrano, R. and V. Pinilla (2012) The long-run decline in the share of agricultural and food products in international trade: a gravity equation approach to its causes. Applied Economics, 44, 4199-4210

Serrano, R. and V. Pinilla (2016) The declining role of Latin America in global agricultural trade, 1963-2000. Journal of Latin American Studies, 48, 115-146

Su, B. and B.W. Ang (2012) Structural decomposition analysis applied to energy and emissions: Some methodological developments. Energy Economics, 34, 177-188

Tang, J.P. (2015) Pollution havens and the trade in toxic chemicals: Evidence from U.S. trade flows. Ecological Economics, 112, 150-160

Temurshoev, U., R.E. Miller and M.C. Bouwmeester (2013) A note on the gras method. Economic Systems Research, 25, 361-367 
Timmer, M.P., E. Dietzenbacher, B. Los, R. Stehrer and G.J. de Vries (2015) An Illustrated User Guide to the World Input-Output Database: the Case of Global Automotive Production. Review of International Economics, 23, 575-605

Tinbergen, J. (1962) Shaping the World Economy; Suggestions for an International Economic Policy. New York, Twentieth Century Fund

Tukker, A., E. Poliakov, R. Heijungs, T. Hawkins, F. Neuwahl, J.M. Rueda-Cantuche, S. Giljum, S. Moll, J. Oosterhaven and M. Bouwmeester (2009) Towards a global multiregional environmentally extended input-output database. Ecological Economics, 68, 1928-1937

Wang, H., B.W. Ang and B. Su (2017) Assessing drivers of economy-wide energy use and emissions: IDA versus SDA. Energy Policy, 107, 585-599

Wiedmann, T. (2009) A review of recent multi-region input-output models used for consumption-based emission and resource accounting. Ecological Economics, 69, $211-222$

Wiedmann, T., M. Lenzen, K. Turner and J. Barrett (2007) Examining the global environmental impact of regional consumption activities - Part 2: Review of inputoutput models for the assessment of environmental impacts embodied in trade. Ecological Economics, 61, 15-26

World Bank (2016) World Development Indicators. Washington D.C. Retrieved from http://data.worldbank.org/indicator

WRI (2015) CAIT Climate Data Explorer. Washington D.C. Retrieved from http://cait.wri.org/

$\mathrm{Xu}, \mathrm{Y}$. and E. Dietzenbacher (2014) A structural decomposition analysis of the emissions embodied in trade. Ecological Economics, 101, 10-20

Yang, Z., H. Liu, X. Xu and T. Yang (2016) Applying the Water Footprint and dynamic Structural Decomposition Analysis on the growing water use in China during 19972007. Ecological Indicators, 60, 634-643

Yotov, Y.V., R. Piermartini, J.A. Monteiro and M. Larch (2016) An Advanced Guide to Trade Policy Analysis: The Structural Gravity Model. Geneva, WTO and UN

Yu, Y., K. Feng and K. Hubacek (2013) Tele-connecting local consumption to global land 
use. Global Environmental Change, 23, 1178-1186

Zhang, Z., K. Zhu and G.J.D. Hewings (2017) A multi-regional input-output analysis of the pollution haven hypothesis from the perspective of global production fragmentation. Energy Economics, 64, 13-23 
Figure 1Figurew

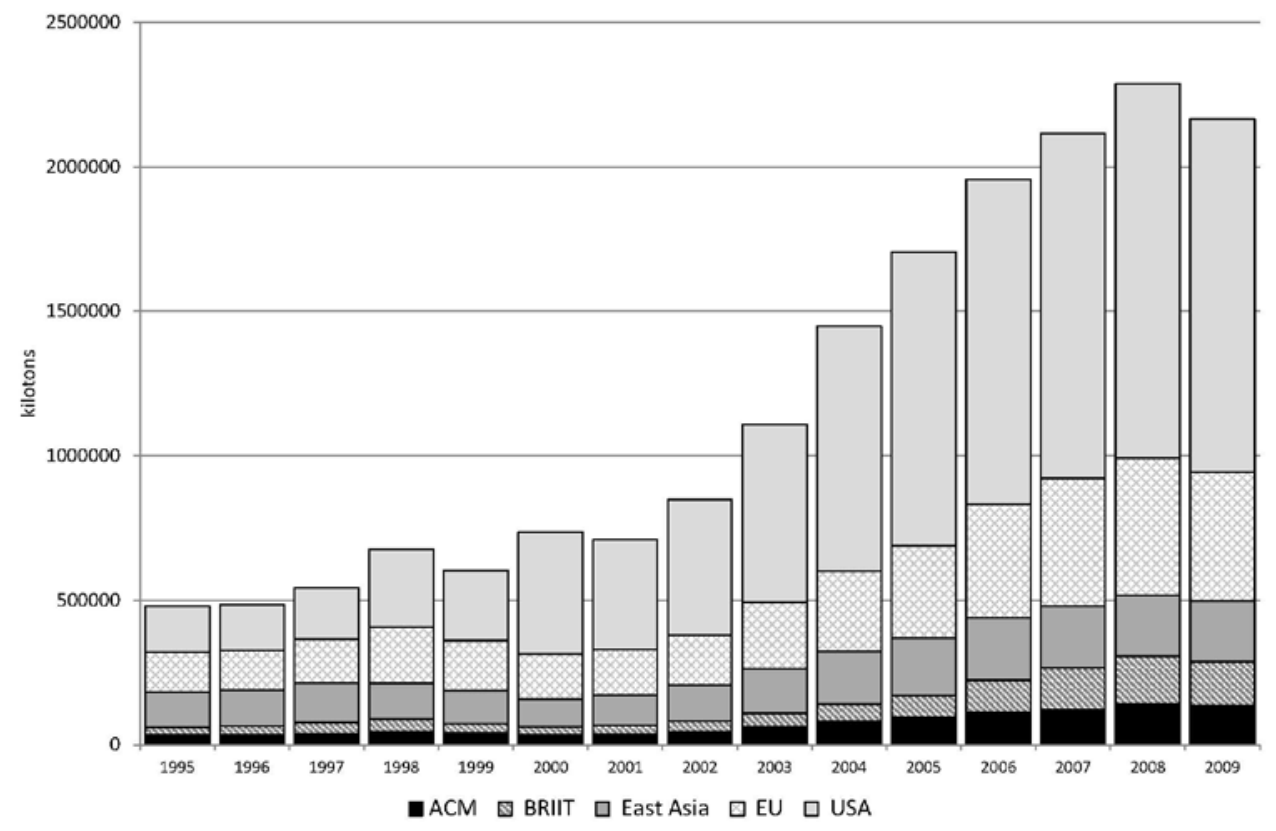

Figure 2

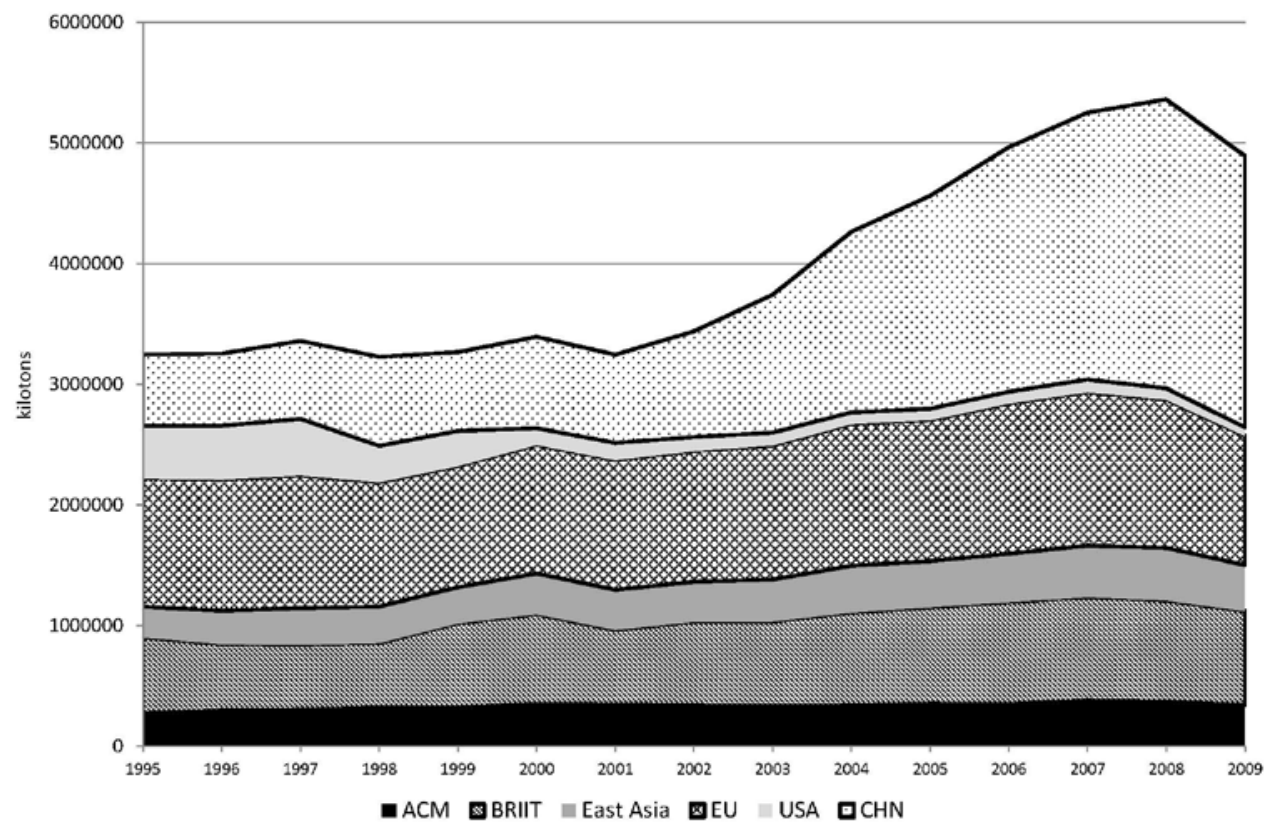


Table 1: Summary statistics

\begin{tabular}{lrrrrr}
\hline Variable & Observations & Mean & Std. Dev. & Min & Max \\
\hline CO2_EE (kilotonnes) & 22,230 & 2,481 & 21,367 & 0 & $1,296,560$ \\
POPULATION (inhabitants) & 22,230 & $1.04 * 10^{8}$ & $2.59 * 10^{8}$ & 370,433 & $1.33^{*} 10^{9}$ \\
GDP per capita (2005\$) & 22,230 & 21,849 & 16,760 & 469 & 86,127 \\
DISTANCE (KM) & 22,230 & 4,971 & 4,459 & 60 & 18,550 \\
CONTIGUITY & 22,230 & 0.61 & 0.24 & 0 & 1 \\
BOTHIN & 22,230 & 0.83 & 0.37 & 0 & 1 \\
RTA & 22,230 & 0.43 & 0.50 & 0 & 1 \\
ENERGY (Kg per capita) & 22,230 & $3,507.6$ & $1,908.9$ & 399.5 & $9,419.0$ \\
Kyoto & 22,230 & 0.28 & 0.44 & 0 & 1 \\
\hline
\end{tabular}

Table 2: Trade gravity estimates using carbon embodied in exports as dependent

\begin{tabular}{|c|c|c|c|c|c|}
\hline & $\begin{array}{l}(1) \\
\text { OLS }\end{array}$ & $\begin{array}{c}(2) \\
\text { PPML }\end{array}$ & $\begin{array}{c}\text { (3) } \\
\text { OLS-MRT }\end{array}$ & $\begin{array}{c}(4) \\
\text { PPML-MRT }\end{array}$ & $\begin{array}{c}(5) \\
\text { PPML-MRT-ENDOG. }\end{array}$ \\
\hline POP_e & $\begin{array}{l}1.014 * * * \\
(0.0153)\end{array}$ & $\begin{array}{c}0.884^{* * *} \\
(0.0826)\end{array}$ & & & \\
\hline POP_i & $\begin{array}{c}0.784 * * * \\
(0.0158)\end{array}$ & $\begin{array}{l}1.012 * * * \\
(0.0742)\end{array}$ & & & \\
\hline GDPpc_e & $\begin{array}{c}-0.288^{* * * *} \\
(0.0372)\end{array}$ & $\begin{array}{c}-0.581^{* * *} \\
(0.142)\end{array}$ & & & \\
\hline GDPpc_i & $\begin{array}{c}0.947 * * * \\
(0.0375)\end{array}$ & $\begin{array}{c}0.667 * * * \\
(0.0929)\end{array}$ & & & \\
\hline DISTANCE & $\begin{array}{c}-0.806^{* * * *} \\
(0.0303)\end{array}$ & $\begin{array}{c}-0.450 * * * \\
(0.0689)\end{array}$ & $\begin{array}{c}-0.955^{* * *} \\
(0.0374)\end{array}$ & $\begin{array}{c}-0.552^{* * *} \\
(0.0515)\end{array}$ & \\
\hline CONTIGUITY & $\begin{array}{c}0.483 * * * \\
(0.0973)\end{array}$ & $\begin{array}{r}-0.0323 \\
(0.237)\end{array}$ & $\begin{array}{c}0.339 * * * \\
(0.0900)\end{array}$ & $\begin{array}{l}0.231^{* *} \\
(0.0980)\end{array}$ & \\
\hline ENERGY_e & $\begin{array}{l}1.478 * * * \\
(0.0652)\end{array}$ & $\begin{array}{c}1.386 * * * \\
(0.249)\end{array}$ & & & \\
\hline ENERGY_i & $\begin{array}{l}-0.0788 \\
(0.0678)\end{array}$ & $\begin{array}{c}0.762 * * * \\
(0.220)\end{array}$ & & & \\
\hline кYOTO & $\begin{array}{l}-0.0137 \\
(0.0199)\end{array}$ & $\begin{array}{l}-0.0197 \\
(0.0633)\end{array}$ & $\begin{array}{l}0.298^{*} \\
(0.171)\end{array}$ & $\begin{array}{l}-0.277^{*} \\
(0.159)\end{array}$ & $\begin{array}{c}-0.154^{* * *} \\
(0.0401)\end{array}$ \\
\hline RTA & $\begin{array}{l}-0.110^{* *} \\
(0.0511)\end{array}$ & $\begin{array}{c}0.447 \\
(0.273)\end{array}$ & $\begin{array}{l}-0.0165 \\
(0.0526)\end{array}$ & $\begin{array}{c}0.387^{* *} \\
(0.153)\end{array}$ & $\begin{array}{l}0.107 * * * \\
(0.0320)\end{array}$ \\
\hline BOTHIN & $\begin{array}{l}0.0308 \\
(0.0495)\end{array}$ & $\begin{array}{l}0.404^{*} \\
(0.224)\end{array}$ & $\begin{array}{l}0.303^{*} \\
(0.183)\end{array}$ & $\begin{array}{l}-0.0144 \\
(0.330)\end{array}$ & $\begin{array}{l}-0.218^{*} \\
(0.118)\end{array}$ \\
\hline Constant & $\begin{array}{c}-56.47^{* * *} \\
(0.785)\end{array}$ & $\begin{array}{c}-61.91 * * * \\
(4.960)\end{array}$ & $\begin{array}{c}-4.215^{* * *} \\
(0.451)\end{array}$ & $\begin{array}{c}-8.383^{* * *} \\
(0.692)\end{array}$ & $\begin{array}{c}-13.06^{* * *} \\
(0.227)\end{array}$ \\
\hline Observations & 22,229 & 22,230 & 22,229 & 22,229 & 22,229 \\
\hline R-squared & 0.843 & 0.707 & 0.946 & 0.970 & 0.999 \\
\hline RESET (p-value) & 0 & 0 & 0.0065 & 0 & 0.9562 \\
\hline Country-time FE & NO & NO & YES & YES & YES \\
\hline Pair FE & NO & NO & NO & NO & YES \\
\hline
\end{tabular}


Table 3: Trade gravity estimates by country groups using carbon embodied in exports as dependent

\begin{tabular}{|c|c|c|c|c|c|c|c|c|c|c|c|c|c|c|c|}
\hline \multirow[b]{2}{*}{ VARIABLES } & (NA1-1) & (NA1-2) & (NA1-3) & (NA1-4) & (NA1-5) & (EIT-1) & (EIT-2) & (EIT-3) & (EIT-4) & (EIT-5) & $(A 2-1)$ & (A2-2) & $(\mathrm{A} 2-3)$ & (A2-4) & $(A 2-5)$ \\
\hline & OLS & PPML & OLS-MRT & PPML-MRT & $\begin{array}{c}\text { PPML-MRT } \\
\text { ENDOG. }\end{array}$ & OLS & PPML & OLS-MRT & PPML-MRT & $\begin{array}{l}\text { PPML-MRT } \\
\text { ENDOG. }\end{array}$ & OLS & PPML & OLS-MRT & PPML-MRT & $\begin{array}{c}\text { PPML-MRT } \\
\text { ENDOG. }\end{array}$ \\
\hline & \multicolumn{5}{|c|}{ Panel a: NA1 countries } & \multicolumn{5}{|c|}{ Panel b: EIT countries } & \multicolumn{5}{|c|}{ Panel c: A2 countries } \\
\hline \multirow[t]{2}{*}{ POP_e } & $0.882 * * *$ & $1.060 * * *$ & & & & $1.050 * * *$ & $0.983^{* * *}$ & & & & $0.879 * * *$ & $0.656^{* * *}$ & & & \\
\hline & $(0.0944)$ & $(0.122)$ & & & & $(0.0266)$ & $(0.0515)$ & & & & $(0.0263)$ & $(0.0391)$ & & & \\
\hline \multirow[t]{2}{*}{ POP_i } & $0.930 * * *$ & $1.136^{* * *}$ & & & & $0.696 * * *$ & $0.861^{* * *}$ & & & & $0.783^{* * *}$ & $0.944 * * *$ & & & \\
\hline & $(0.0360)$ & $(0.0303)$ & & & & $(0.0263)$ & $(0.0681)$ & & & & $(0.0206)$ & $(0.0386)$ & & & \\
\hline \multirow[t]{2}{*}{ GDPpc_e } & $-1.133^{* * *}$ & $-1.036^{* * *}$ & & & & $-0.642^{* * *}$ & $-0.408 * * *$ & & & & 0.101 & -0.273 & & & \\
\hline & $(0.157)$ & $(0.253)$ & & & & (0.0779) & $(0.114)$ & & & & $(0.101)$ & $(0.210)$ & & & \\
\hline \multirow[t]{2}{*}{ GDPpc_i } & $1.191^{* * *}$ & $0.846^{* * *}$ & & & & $0.640 * * *$ & $0.563^{* * *}$ & & & & $1.103 * * *$ & $0.687^{* * *}$ & & & \\
\hline & $(0.0697)$ & $(0.0752)$ & & & & $(0.0572)$ & $(0.0975)$ & & & & $(0.0516)$ & $(0.0880)$ & & & \\
\hline \multirow[t]{2}{*}{ DISTANCE } & $-0.685^{* * *}$ & $-0.118 * * *$ & $-0.760 * * *$ & $-0.444 * * *$ & & $-0.843 * * *$ & $-1.003 * * *$ & $-1.102^{* * *}$ & $-0.600 * * *$ & & $-0.683 * * *$ & $-0.441 * * *$ & $-0.819 * * *$ & $-0.434 * * *$ & \\
\hline & $(0.147)$ & $(0.0456)$ & $(0.127)$ & $(0.134)$ & & $(0.0438)$ & $(0.129)$ & $(0.0992)$ & $(0.114)$ & & $(0.0460)$ & $(0.0722)$ & $(0.0503)$ & $(0.0387)$ & \\
\hline \multirow[t]{2}{*}{ CONTIGUITY } & $0.787^{* *}$ & $0.378^{* *}$ & 0.0930 & $0.323^{* *}$ & & $0.663^{* * *}$ & 0.200 & $0.474^{* * *}$ & $0.364^{* * *}$ & & $0.369 * * *$ & $0.268^{* *}$ & 0.161 & $0.350 * * *$ & \\
\hline & $(0.348)$ & -0.169 & $(0.213)$ & $(0.151)$ & & $(0.139)$ & $(0.181)$ & (0.124) & $(0.0843)$ & & $(0.121)$ & $(0.129)$ & $(0.117)$ & (0.0959) & \\
\hline \multirow[t]{2}{*}{ ENERGY_e } & $2.867 * * *$ & $2.876^{* * *}$ & & & & $1.975^{* * *}$ & $1.215^{* * *}$ & & & & $0.602 * * *$ & $0.705^{* * *}$ & & & \\
\hline & $(0.250)$ & $(0.287)$ & & & & $(0.123)$ & $(0.187)$ & & & & $(0.105)$ & $(0.169)$ & & & \\
\hline \multirow[t]{2}{*}{ ENERGY_i } & -0.113 & $0.720^{* * *}$ & & & & $0.300 * * *$ & $0.477^{* * *}$ & & & & $-0.302 * * *$ & $0.514^{* * *}$ & & & \\
\hline & $(0.142)$ & $(0.104)$ & & & & $(0.103)$ & $(0.137)$ & & & & $(0.0913)$ & $(0.150)$ & & & \\
\hline \multirow[t]{2}{*}{ кYОто } & -0.0350 & $-0.348 * * *$ & 0.155 & 0.297 & $-0.175^{* * *}$ & $0.0843^{* *}$ & -0.0891 & -0.148 & $-1.391 * * *$ & 0.173 & $-0.0801 * * *$ & -0.0594 & 0.104 & 0.0156 & $-0.150 * * *$ \\
\hline & $(0.0453)$ & $(0.0656)$ & $(0.254)$ & $(0.343)$ & $(0.0448)$ & $(0.0375)$ & $(0.0556)$ & $(0.242)$ & $(0.149)$ & $(0.236)$ & $(0.0281)$ & $(0.0485)$ & $(0.179)$ & $(0.117)$ & $(0.0430)$ \\
\hline \multirow[t]{2}{*}{ RTA } & $-0.249 *$ & $0.729 * * *$ & $0.492^{* * *}$ & $0.725^{* * *}$ & 0.0282 & 0.0644 & 0.0331 & 0.0418 & 0.130 & $0.132^{* *}$ & $-0.309 * * *$ & 0.144 & $0.224 * *$ & $0.488^{* * *}$ & $0.192^{* * *}$ \\
\hline & $(0.132)$ & $(0.190)$ & $(0.118)$ & $(0.153)$ & $(0.0651)$ & $(0.0632)$ & $(0.163)$ & $(0.0802)$ & $(0.0921)$ & $(0.0581)$ & $(0.0831)$ & $(0.145)$ & $(0.0877)$ & $(0.106)$ & $(0.0380)$ \\
\hline \multirow[t]{2}{*}{ BOTHIN } & $0.176^{* *}$ & $0.361^{* * *}$ & -0.152 & $-0.729 * * *$ & $-0.716^{* * *}$ & $0.243^{* * *}$ & $0.189 * *$ & -0.0718 & 0.00568 & -0.00886 & -0.0705 & $0.283^{*}$ & $-0.797 * * *$ & $-1.052^{* * *}$ & $1.292^{* * *}$ \\
\hline & $(0.0827)$ & $(0.0853)$ & (0.118) & $(0.264)$ & (0.193) & $(0.0685)$ & $(0.0946)$ & $(0.200)$ & $(0.163)$ & $(0.0721)$ & $(0.0924)$ & $(0.165)$ & $(0.246)$ & $(0.211)$ & (0.0819) \\
\hline \multirow[t]{2}{*}{ Constant } & $-62.69 * * *$ & $-79.17^{* * *}$ & $-8.160 * * *$ & $-10.21^{* * *}$ & $-10.81^{* * *}$ & $-56.44 * * *$ & $-53.20 * * *$ & $-5.970 * * *$ & $-7.596^{* * *}$ & $-18.93^{* * *}$ & $-51.29 * * *$ & $-51.98 * * *$ & $-4.842 * * *$ & $-8.226^{* * *}$ & $-16.53^{* * *}$ \\
\hline & $(3.270)$ & (2.689) & $(1.263)$ & $(1.268)$ & $(0.0780)$ & (1.314) & (1.173) & $(0.748)$ & (0.818) & $(0.634)$ & $(1.330)$ & $(2.309)$ & $(0.670)$ & $(0.546)$ & $(0.0853)$ \\
\hline Observations & 2,850 & 2,850 & 2,850 & 2,850 & 2,850 & 7,409 & 7,410 & 7,409 & 7,409 & 7,409 & 11,400 & 11,400 & 11,400 & 11,400 & 11,400 \\
\hline R-squared & 0.914 & 0.984 & 0.979 & 0.999 & 1.000 & 0.887 & 0.821 & 0.952 & 0.953 & 0.994 & 0.804 & 0.804 & 0.951 & 0.968 & 0.998 \\
\hline RESET ( $p$-value) & 0.1811 & 0.0001 & 0.313 & 0.0099 & 0.2924 & 0.01 & 0.0091 & 0.0257 & 0.4161 & 0.7837 & 0.0672 & 0.0114 & 0 & 0.0114 & 0.0654 \\
\hline Country-time FE & NO & NO & YES & YES & YES & NO & NO & YES & YES & YES & NO & NO & YES & YES & YES \\
\hline Pair FE & NO & NO & NO & NO & YES & NO & NO & NO & NO & YES & NO & NO & NO & NO & YES \\
\hline
\end{tabular}

Clustered standard errors in parentheses. ${ }^{* * *} p<0.01,{ }^{* *} p<0.05,{ }^{*} p<0 . \overline{1}$ 


\section{Supplementary information}

Figure SI1: Change in CO2 emissions embodied in bilateral exports, 1995-2009. The vertical axis informs on the exporter countries and the legend on the importers. Source: own elaboration from WIOD (2012) and Genty et al. (2012).

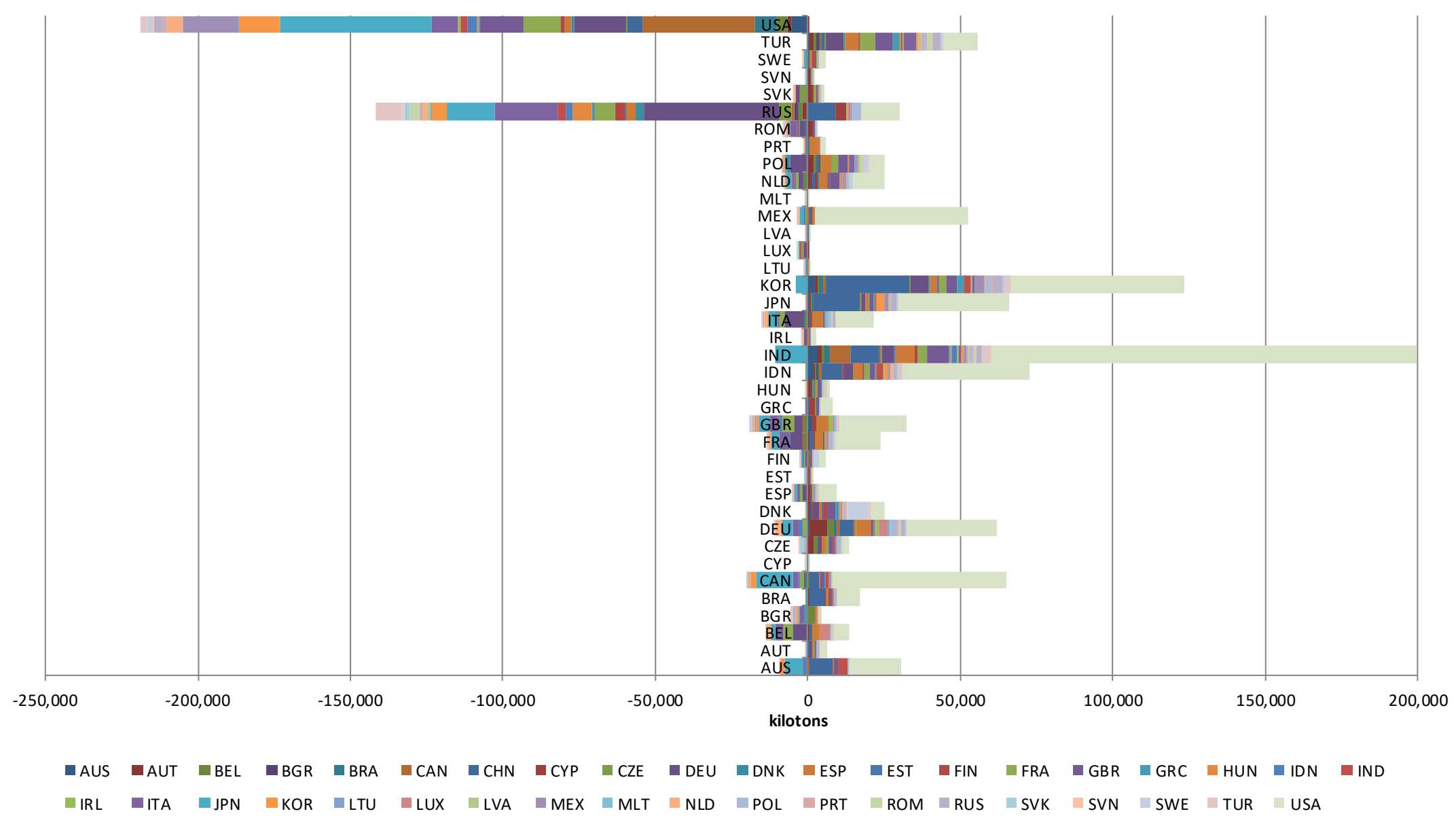




\section{Country list}

See the United Nations Framework Convention on Climate Change (UNFCCC) website for more informationon the Kyoto protocol and country groups.

http://unfccc.int/kyoto protocol/items/2830.php

\section{Non-Annex 1 countries (NA1)}

Brazil, China, Indonesia, India, Mexico

\section{Annex 2 countries (A2)}

Australia, Austria, Belgium, Canada, Germany, Denmark, Spain, Finland, France, Great Britain, Greece, Ireland, Italy, Japan, Korea, Luxembourg, Netherlands, Portugal, Sweden, Turkey, United States.

\section{Economies in transition (EIT)}

Bulgaria, Cyprus, Czech Republic, Estonia, Hungary, Lithuania, Latvia, Malta, Poland, Romania, Russian Federation, Slovak Republic, Slovenia 
Table SI1: CO2 gravity estimates using carbon in gross exports as dependent

\begin{tabular}{|c|c|c|c|c|c|}
\hline & $\begin{array}{l}\text { (1) } \\
\text { OLS }\end{array}$ & $\begin{array}{c}(2) \\
\text { PPML }\end{array}$ & $\begin{array}{c}\text { (3) } \\
\text { OLS-MRT }\end{array}$ & $\begin{array}{c}(4) \\
\text { PPML-MRT }\end{array}$ & $\begin{array}{c}(5) \\
\text { PPML-MRT-ENDOG }\end{array}$ \\
\hline \multirow{2}{*}{ POP_e } & $1.079 * * *$ & $0.680 * * *$ & & & \\
\hline & $(0.0187)$ & $(0.0376)$ & & & \\
\hline \multirow[t]{2}{*}{ POP_i } & $0.853 * * *$ & $0.854 * * *$ & & & \\
\hline & (0.0179) & $(0.0357)$ & & & \\
\hline \multirow[t]{2}{*}{ GDPpc_e } & $-0.129 * * *$ & $-0.272 * * *$ & & & \\
\hline & (0.0479) & (0.0754) & & & \\
\hline \multirow[t]{2}{*}{ GDPpc_i } & $0.872 * * *$ & $0.693 * * *$ & & & \\
\hline & $(0.0456)$ & $(0.0831)$ & & & \\
\hline \multirow[t]{2}{*}{ DISTANCE } & $-1.069 * * *$ & $-0.647 * * *$ & $-1.303 * * *$ & $-0.664 * * *$ & \\
\hline & $(0.0397)$ & $(0.0608)$ & $(0.0551)$ & $(0.0560)$ & \\
\hline \multirow[t]{2}{*}{ CONTIGUITY } & $0.554 * * *$ & $0.404^{* * *}$ & $0.359 * * *$ & $0.463 * * *$ & \\
\hline & (0.117) & $(0.132)$ & $(0.122)$ & $(0.106)$ & \\
\hline \multirow[t]{2}{*}{ ENERGY_e } & $1.426 * * *$ & $0.996 * * *$ & & & \\
\hline & $(0.0803)$ & (0.118) & & & \\
\hline \multirow[t]{2}{*}{ ENERGY_i } & $0.157 * *$ & $0.427 * * *$ & & & \\
\hline & (0.0793) & (0.148) & & & \\
\hline \multirow[t]{2}{*}{ KYOTO } & 0.0169 & -0.0339 & $0.523 * *$ & -0.110 & $-0.223 * * *$ \\
\hline & (0.0237) & (0.0386) & $(0.250)$ & (0.221) & $(0.0820)$ \\
\hline \multirow[t]{2}{*}{ RTA } & -0.0972 & -0.0616 & $-0.150 *$ & 0.0398 & $0.132 * *$ \\
\hline & $(0.0646)$ & $(0.161)$ & $(0.0806)$ & (0.158) & $(0.0537)$ \\
\hline \multirow[t]{2}{*}{ BOTHIN } & $0.247 * * *$ & 0.0511 & 0.365 & 0.207 & -0.123 \\
\hline & $(0.0635)$ & $(0.124)$ & $(0.260)$ & $(0.301)$ & $(0.0840)$ \\
\hline \multirow[t]{2}{*}{ Constant } & $-60.05 * * *$ & $-51.43 * * *$ & $-4.797 * * *$ & $-8.663 * * *$ & $-14.04 * * *$ \\
\hline & $(0.926)$ & $(1.891)$ & $(0.708)$ & (0.710) & $(0.405)$ \\
\hline Observations & 22,220 & 22,230 & 22,220 & 22,230 & 22,230 \\
\hline R-squared & 0.800 & 0.729 & 0.882 & 0.842 & 0.993 \\
\hline \multicolumn{6}{|l|}{ RESET ( $p$-value) } \\
\hline Country-time FE & NO & NO & YES & YES & YES \\
\hline Pair FE & NO & NO & NO & NO & YES \\
\hline
\end{tabular}

Table SI2: Comparison of partial R2s for geographical variables conditioned on the dependent variable

\begin{tabular}{lrr}
\hline & \multicolumn{2}{c}{ Partial R2 } \\
\hline Dependent: & Carbon in direct exports & Carbon embodied in exports \\
\hline DISTANCE & 5.6 & 3.3 \\
CONTIGUITY & 4.9 & 3.8 \\
\hline
\end{tabular}

The model was estimated using population, per capita GDP, distance, contiguity, energy use, Kyoto, RTA and BOTHIN as regressors. 